\title{
A NUMERICAL ANALYSIS ON FLAT-SHAPED RC BEAMS UNDER FALLING-WEIGHT IMPACT LOADING
}

\author{
DANDAN ZHENG ${ }^{1}$, MASATO KOMURO ${ }^{2}$, TOMOKI KAWARAI ${ }^{1} \&$ NORIMITSU KISHI $^{3}$ \\ ${ }^{1}$ Division of Engineering, Muroran Institute of Technology, Japan \\ ${ }^{2}$ College of Environmental Technology, Muroran Institute of Technology, Japan \\ ${ }^{3}$ National Institute of Technology, Kushiro College, Japan
}

\begin{abstract}
In this study, in order to establish a rational numerical analysis method for RC structures under fallingweight impact loading, a 3D elasto-plastic dynamic response analysis was conducted for flat-shaped $\mathrm{RC}$ beams. The beams have a rectangular cross section of $150 \times 450 \mathrm{~mm}$ (height $\times$ width) and a clear span length of $2.0 \mathrm{~m}$, which are an approximate one-fifth scale of the roof slab of existing RC rockfall protection galleries. Falling-weight impact tests were conducted by dropping a $300 \mathrm{~kg}$ steel weight onto the mid-span of the beam. Here, an influence of the element size of FE analysis on numerical simulation dynamic responses of the flat-shaped $\mathrm{RC}$ beams was investigated by dividing the intervals of stirrups $(125 \mathrm{~mm})$ into $2,5,10$ elements, in which these element sizes were $62.5 \mathrm{~mm}, 25 \mathrm{~mm}, 12.5 \mathrm{~mm}$, respectively. An appropriate element size was determined comparing with the experimental results of the impact and reaction forces, the deflection at the loading point, and the crack patterns occurred on surfaces of the beam after the experiment. The results obtained from this study were as follows: 1) the time histories of the dynamic responses of the flat-shaped RC beams can be better simulated using a 25 $\mathrm{mm}$ of element size in span direction; and 2) maximum and residual deflections can be better predicted in spite of the magnitude of the falling height of the weight; 3 ) crack patterns of the RC beams can be better simulated applying the proposed numerical analysis method.
\end{abstract}

Keywords: flat-shaped RC beam, finite element analysis, element size, impact loading.

\section{INTRODUCTION}

In Japan, the structural design concept for infrastructures tends to be shifted from "allowable stress design method" to "performance-based design method" through "limit state design method". Under this situation, in order to establish the performance-based design method for the impact resistant structures such as RC rock-sheds, steel wire nets, and fences, many experiments [1]-[4] have been done to accumulate the fundamental knowledge on impact resistant characteristics of these members and/or structures. However, it is not easy to conduct the experimental studies because of high cost and time consuming. Therefore, to achieve this goal more effectively, the numerical analysis studies [5], [6] also should be conducted.

From this point of view, in this study, to establish a rational numerical analysis method for RC structures under falling-weight impact loading, a 3D elasto-plastic dynamic response analysis with a simple constitutive model for concrete was conducted for the flat-shaped RC beams. First of all, an appropriate element size for FE analysis was determined comparing with the experimental results [7] and numerical ones. Here, the experimental results of the impact and reaction forces, the deflection at the loading point, and crack patterns on the surfaces of the beams after the experiment were used for the comparisons. Falling height of the steel weight was varied from 0.25 to $1.5 \mathrm{~m}$. And, LS-DYNA [8] commercial program (ver. R9) was used for this study.

\section{OUTLINE OF EXPERIMENTS}

Fig. 1 shows dimensions and rebar arrangement of the flat-shaped RC beams used in this study, which are an approximate one-fifth scale of the roof slab of the existing RC rockfall 


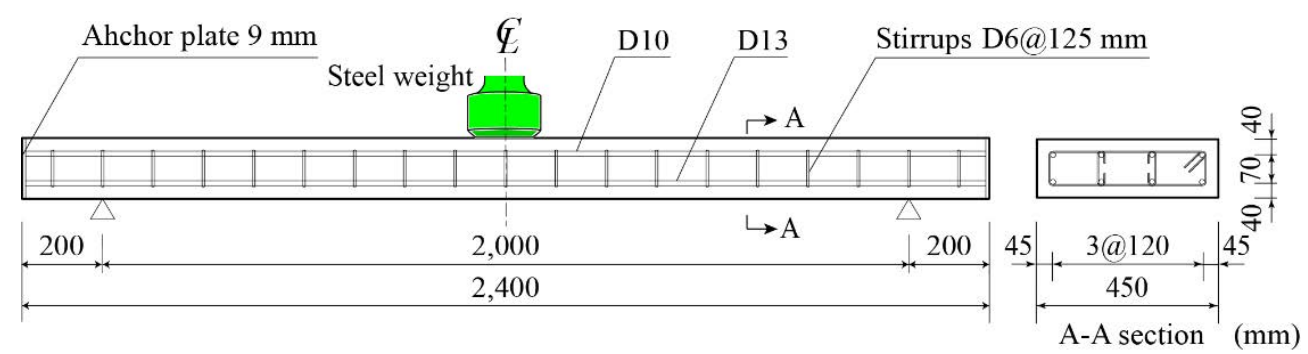

Figure 1: Dimensions and rebar arrangement of flat-shaped RC beams.

protection galleries. The beams have a rectangular cross section of $150 \times 450 \mathrm{~mm}$ (height $\times$ width) and a clear span length of $2.0 \mathrm{~m}$. Four deformed rebars of diameter $\phi=10 \mathrm{~mm}$ and 13 $\mathrm{mm}$ were placed at the upper and lower fibers, respectively, and were welded to the anchor plate having $t=9 \mathrm{~mm}$ thickness at the ends of the beam to save the anchorage length. The rebar ratios in the compression and tension sides were about $0.42 \%$ and $0.75 \%$, respectively. Stirrups of diameter $\phi=6 \mathrm{~mm}$ were placed every $125 \mathrm{~mm}$. Depth of the concrete cover were set as $40 \mathrm{~mm}$. At commencement of the experiments, average compressive strength of the concrete was $25.2 \mathrm{~N} / \mathrm{mm}^{2}$, and yield strength of the main rebars D10, D13 and stirrups D6 were $379,383,363 \mathrm{~N} / \mathrm{mm}^{2}$, respectively, obtained from the coupon tests as shown in Table 1.

In this experiment, the impact force was singly loaded due to freely falling a $300 \mathrm{~kg}$ steel weight from a prescribed height onto the mid-span of the beam, and falling height of the steel weight was varied from $0.25 \mathrm{~m}$ to $1.5 \mathrm{~m}$. The weight was made of a steel solid cylinder with a height of $1.4 \mathrm{~m}$ and a diameter of $200 \mathrm{~mm}$ for the striking part, and its impacting surface has a taper with a height of $2 \mathrm{~mm}$ to prevent one-sided contact. The beam was placed on the supports equipped with load cells and was clamped using cross beams to prevent lifting off. Only the rotation at the bottom of the supports was allowed. Fig. 2 shows the experimental setup.

Here, the time histories of the impact force, the total reaction force (hereinafter, reaction force), and the deflection of the lower surface at the loading point (hereinafter, deflection) were measured. The impact force was measured by using a load cell that was installed in the steel weight, and the deflection was measured by using the non-contact laser type linear variable displacement transducers. Crack patterns of the beams were also sketched after the experiment.

Table 1: Mechanical properties of rebars and stirrups.

\begin{tabular}{|l|c|c|c|}
\hline & D6 & D10 & D13 \\
\hline Nominal diameter $\phi(\mathrm{mm})$ & 6 & 10 & 13 \\
\hline Effective cross-sectional area $A_{s}\left(\mathrm{~mm}^{2}\right)$ & 31.67 & 71.33 & 126.7 \\
\hline Yield stress $f_{y}\left(\mathrm{~N} / \mathrm{mm}^{2}\right)$ & 363 & 379 & 383 \\
\hline Ultimate tensile strength $f_{u}\left(\mathrm{~N} / \mathrm{mm}^{2}\right)$ & 542 & 551 & 572 \\
\hline Elastic modulus $E_{s}\left(\mathrm{kN} / \mathrm{mm}^{2}\right)$ & 200 & 200 & 200 \\
\hline Poisson's ratio $v_{s}$ & 0.3 & 0.3 & 0.3 \\
\hline
\end{tabular}




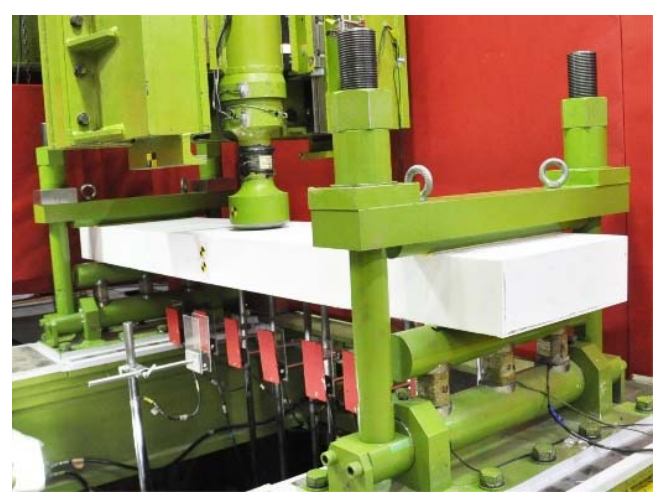

Figure 2: Experimental setup.

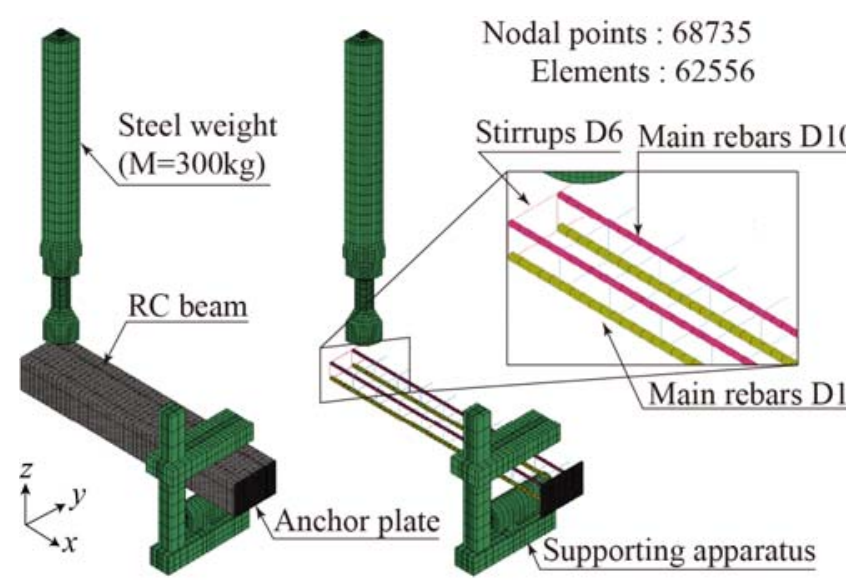

Figure 3: Finite element model of flat-shaped $\mathrm{RC}$ beams $(\mathrm{L}=25 \mathrm{~mm})$.

\section{OVERVIEW OF ANALYSIS}

\subsection{Finite element model}

In this study, an influence of the element size in the span direction of FE analysis on numerical simulation of the dynamic responses for the flat-shaped RC beams was investigated, in which the sizes of $62.5 \mathrm{~mm}, 25 \mathrm{~mm}$, and $12.5 \mathrm{~mm}$ were considered. Fig. 3 shows an example of the FE model with $\mathrm{L}=25 \mathrm{~mm}$ element size for the beam used in this study. Here, one quarter of the RC beam including falling weight and supporting device was modeled considering two symmetries with respect to the mid-span cross section and the central surface in the widthwise direction of the beam. In this model, the stirrups of D6 were modeled using a two-node beam element with $2 \times 2$ Gauss points, which has an equivalent axial stiffness, cross-sectional area, and mass with those of real ones. The other parts were modeled using eight-node solid elements with one integration point. 
The total numbers of nodal points and elements used in this model were about 69,000 and 63,000 , respectively.

Regarding of the boundary condition of FE model, the displacement in the normal direction of the symmetric surface was restrained, and only the rotation around y axis at the bottom of the supporting apparatus was allowed following the experimental conditions. Contact surfaces between concrete and rebar, and between concrete and anchor plate were assumed to be perfectly bonded to each other. Between the impacted surfaces of concrete and the steel weight as well as between contacted concrete surface and the supporting apparatus were defined so as to allow contact or detach or slide to each other. Friction factor of the contact surface was assumed to be 0.25 .

The impact load was applied by inputting an actual impact velocity for all the elements of the falling weight placed on the beam. The damping factor was assumed as $h=1.5 \%$ for the fundamental natural frequency of the vertical vibration mode based on the pre-analysis results. Gravity was taken into consideration in this FE model.

\subsection{Material models}

Fig. 4 shows the stress-strain relationships of concrete and rebar used in this study. In this study, an effect of the strain rate was not considered for all materials, because the impact velocity of the falling weight was relatively small. The constitutive model for each material was briefly described below.

\subsubsection{Concrete}

Fig. 4(a) shows the stress-strain relationship for concrete used in this study. An isotropic elasto-plastic model considering the tensile fracture was defined, in which a bilinear model in the compression side and a cut-off model in the tension side were applied. It is assumed that: 1 ) the concrete yielded at $0.15 \%$ strains and its strength was equal to the compressive strength $f^{\prime}$ c obtained from the static test results; 2 ) the tensile stress was interrupted when an applied negative pressure reaches the tensile strength of concrete $f_{t 0}$; and 3) the tensile strength $f_{t 0}$ was set to be $1 / 10$ of static compressive strength $f_{c}^{\prime}$. Yielding of concrete was evaluated under Dracker-Prager's yield criterion, in which internal friction angle for concrete was set to be $30^{\circ}$. The Young's modulus $E_{c}$, Poisson's ratio $v_{c}$, and the density $\rho_{c}$ were set as $E_{c}=16.8 \mathrm{kN} / \mathrm{mm}^{2}, v_{c}=0.167$, and $\rho_{c}=2.35 \times 10^{3} \mathrm{~kg} / \mathrm{m}^{3}$, respectively.

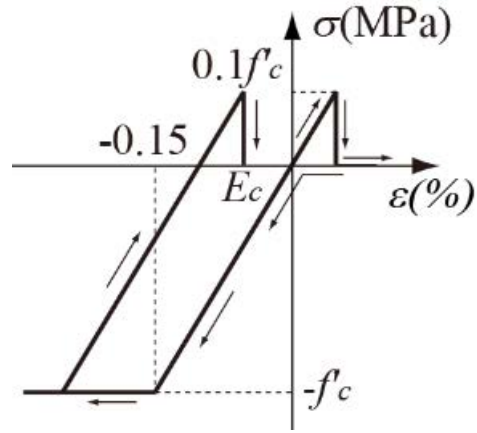

(a)

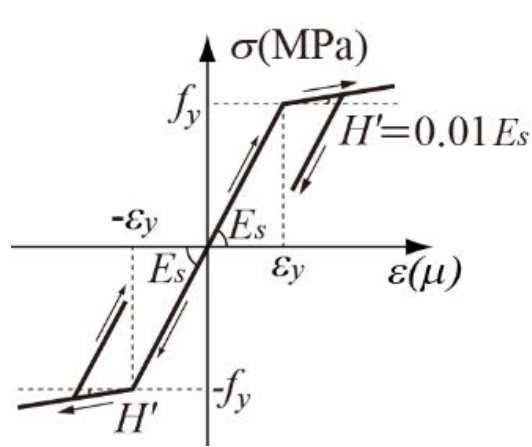

(b)

Figure 4: Stress-strain relationships of materials. (a) Concrete; (b) Rebar and stirrup. 


\subsubsection{Reinforcements}

The stress-strain relationships of axial rebars and stirrups were defined using an isotropic elasto-plastic hardening model considering plastic hardening modulus $H^{\prime}$ as shown in Fig. 4(b). The plastic hardening modulus $H^{\prime}$ was assumed to be $1 \%$ of elastic modulus $E_{s}$. Yielding of rebars and stirrups was evaluated following the von Mises's yield criterion. Density $\rho_{s}$ was set as $\rho_{s}=7.85 \times 10^{3} \mathrm{~kg} / \mathrm{m}^{3}$.

\subsubsection{Falling-weight, supporting apparatus, and anchor plate}

The falling weight, supporting apparatus, and anchor plate were assumed to be elastic body according to the experimental observations because no plastic deformation was observed in the test. Young's modulus $E_{s}$, Poisson's ratio $v_{s}$, and the density $\rho_{s}$ were assumed using static nominal values of steel $\left(E_{s}=200 \mathrm{kN} / \mathrm{mm}^{2}, v_{s}=0.3\right.$, and $\left.\rho_{s}=7.85 \times 10^{3} \mathrm{~kg} / \mathrm{m}^{3}\right)$. Density of the falling weight was evaluated by dividing actual mass by volume of FE model.

\section{NUMERICAL RESULTS AND DISCUSSIONS}

\subsection{Effect of element length}

Fig. 5 shows comparisons of the time histories of (a) the impact force, (b) the reaction force, and (c) the deflection at the lower surface of the span center among numerical results for the cases of various element size and experimental results for $H=1.5 \mathrm{~m}$. In these figures, the origin of time axis was taken as the time when the falling weight impacts the upper surface of the beam.

Fig. 5(a) shows comparisons of time histories of the impact force during a $50 \mathrm{~ms}$ time interval from the beginning of impact. From these figures, it is observed that: 1) configurations of time history of impact forces were composed of the first wave with large amplitude and short time duration; and 2) in the case of $L=62.5 \mathrm{~mm}$, maximum impact force obtained from FE analysis results was better simulated; 3 ) configurations of time history were almost similar to those of experimental results for all cases.

Fig. 5(b) shows comparisons of time histories of the reaction force between numerical and experimental results during a $200 \mathrm{~ms}$ time interval from the beginning of impact. From these figures, it is observed that: 1) configurations of time history of the reaction force were composed of the half sine wave with large amplitude and damping free vibration after that; 2) in the cases of $L=62.5 \mathrm{~mm}$ and $12.5 \mathrm{~mm}$, although the main part of the waves obtained from the numerical results was smaller than that of experimental one, time duration was in good agreement; and 3) on the other hand, in the case of $L=25 \mathrm{~mm}$, configuration of time history of the reaction force was almost similar to each other including maximum value.

Fig. 5(c) shows comparis ons of time his tories of the mid-span deflection between numerical and experimental results for a $200 \mathrm{~ms}$ time interval from the beginning of impact. From these figures, it is seen that: 1) the deflection reached a maximum value at an elapsed time of about $25 \mathrm{~ms}$ from the beginning of impact, and after that the beam was under damping free vibration; 2) in the cases of $L=62.5 \mathrm{~mm}$ and $12.5 \mathrm{~mm}$, the deflections obtained from numerical analysis tend to be evaluated a little larger than those of experimental results; 3 ) on the other hand, in the case of $L=25 \mathrm{~mm}$, time history of the deflection was similar to that of experimental results including maximum and residual deflections.

From the results, it is clarified that the impact resistant behavior of the $\mathrm{RC}$ beam can be better evaluated by dividing into $L=25 \mathrm{~mm}$ element size in the longitudinal direction. The applicability of the proposed condition will be investigated comparing with the experimental results for various falling height in the next section. 

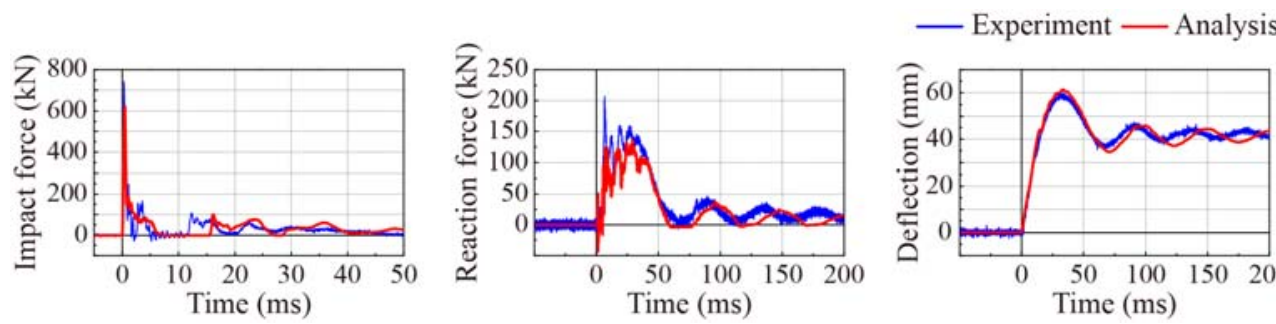

$$
L=62.5 \mathrm{~mm}
$$
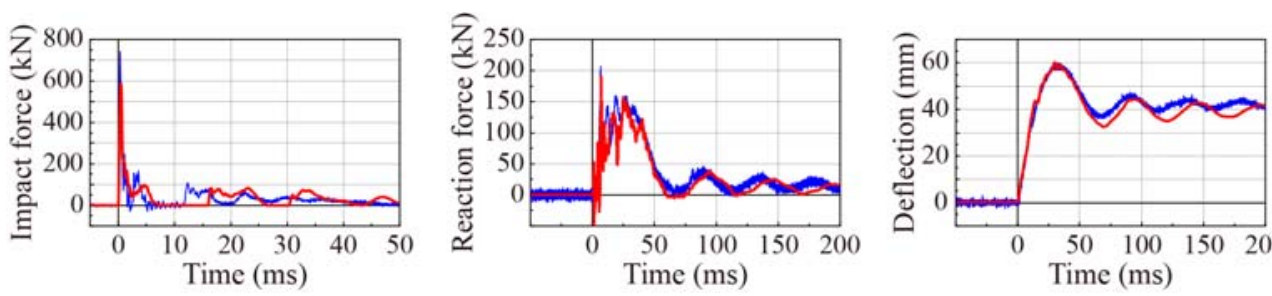

$$
L=25 \mathrm{~mm}
$$

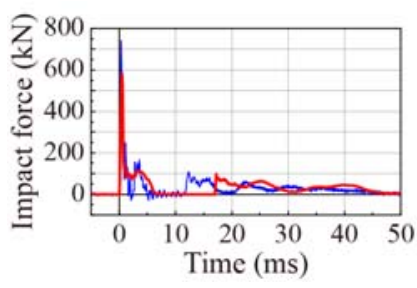

(a)

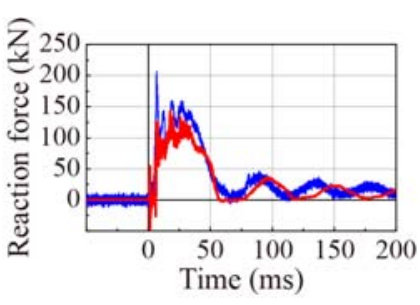

$L=12.5 \mathrm{~mm}$

(b)

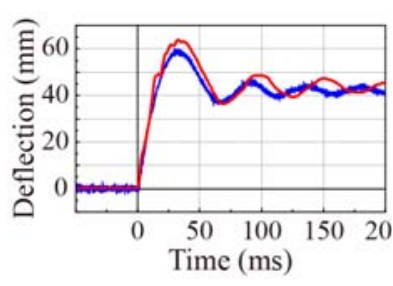

(c)

Figure 5: Comparisons of impact response waves for various element size $(H=1.5 \mathrm{~m})$. (a) Impact force; (b) Reaction force; (c) Deflection.

\subsection{Comparisons of time histories of impact responses for various falling height}

Fig. 6 shows comparisons of time histories of the impact responses for falling heights of $H=$ $0.25,0.5,1.0$, and $1.5 \mathrm{~m}$ between experimental results and numerical ones with element size of $L=25 \mathrm{~mm}$ long.

Fig. 6(a) shows comparisons of time histories of the impact force. From these figures, it is observed that: 1) maximum impact force was increased with an increment of the falling height; 2) although maximum impact forces obtained from the numerical analyses were smaller than those of experimental results, configurations of the time history were almost similar to those of experimental results irrespective of the falling height of the weight.

Fig. 6(b) shows comparisons of time histories of the reaction force. From these figures, it is obtained that: 1) in the cases of falling height of the weight $H=0.5 \mathrm{~m}$ and $1.0 \mathrm{~m}$, although main parts of the reaction force waves obtained from the numerical analysis were smaller than those of the experimental results, time duration was in good agreement with the experimental results; and 2) in the cases of falling height of the weight $H=0.25 \mathrm{~m}$ and 
$1.5 \mathrm{~m}$, configurations of the time histories and maximum values were almost similar to each other.

Fig. 6(c) shows comparisons of time histories of the mid-span deflections. From these figures, it is seen that: 1) maximum and residual deflections tend to be increased with an increment of falling height of the weight; and 2) configurations of time history of the deflection obtained from FE analysis were almost similar to those of experimental results including maximum and residual deflections.
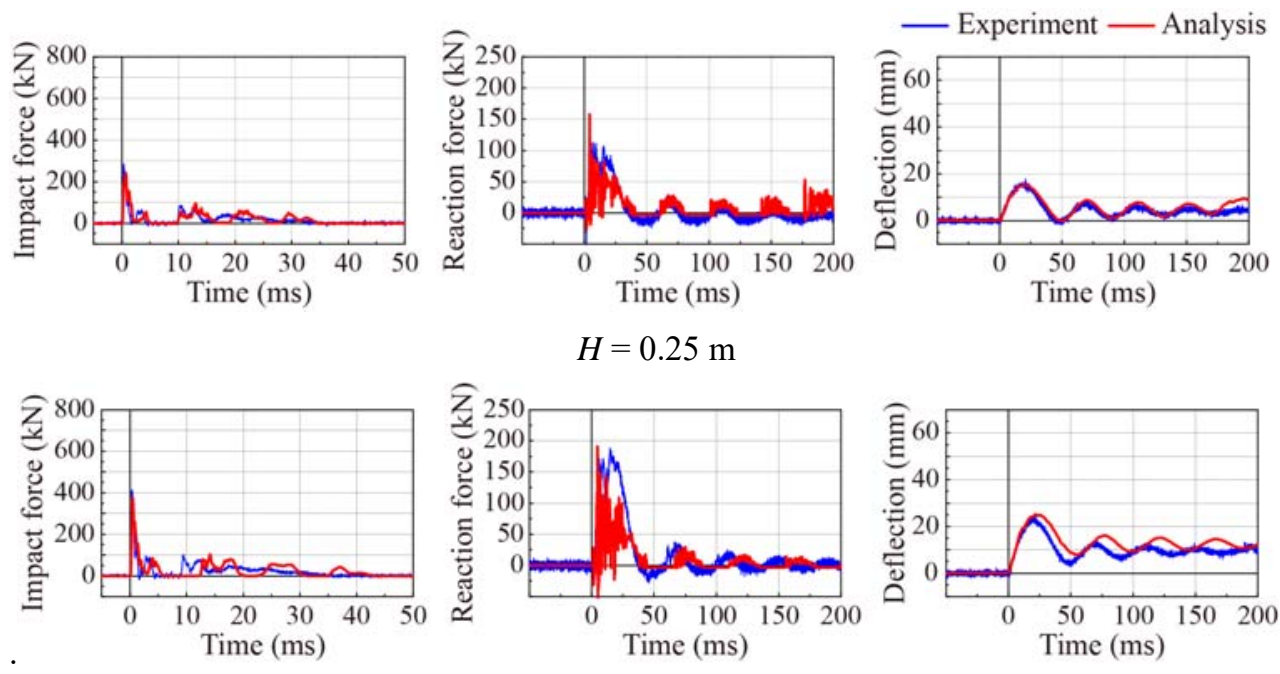

$H=0.5 \mathrm{~m}$
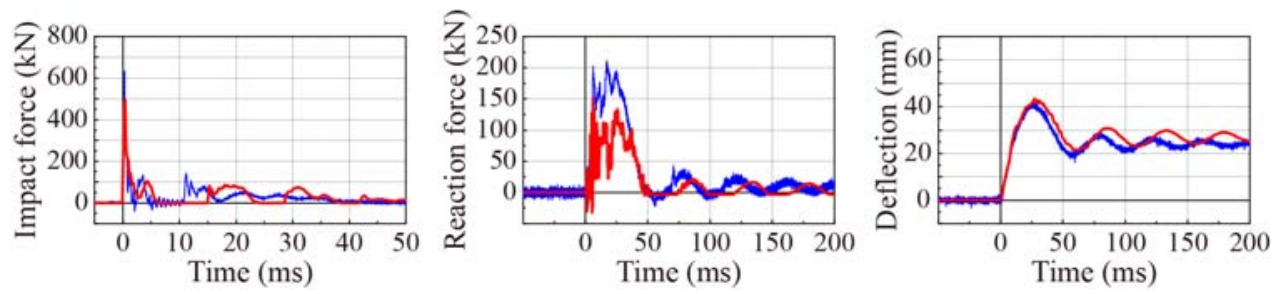

$H=1.0 \mathrm{~m}$

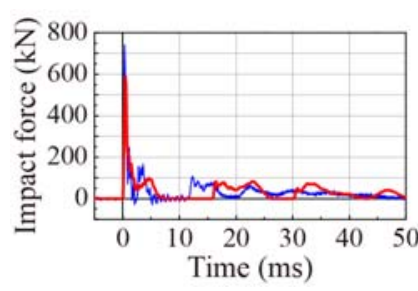

(a)

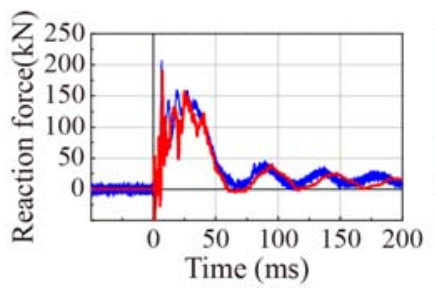

$H=1.5 \mathrm{~m}$

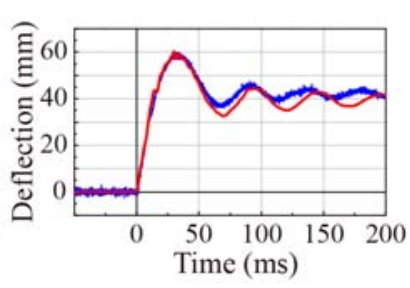

(c)

Figure 6: Comparisons of impact response waves for various falling height in case of using element size of $L=25 \mathrm{~mm}$. (a) Impact force; (b) Reaction force; (c) Deflection. 


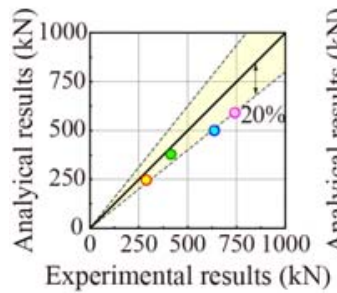

(a)

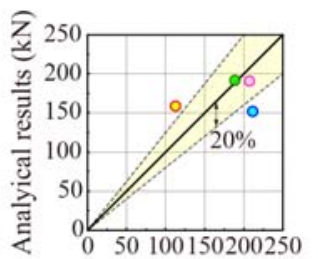

Experimental results $(\mathrm{kN})$

(b)

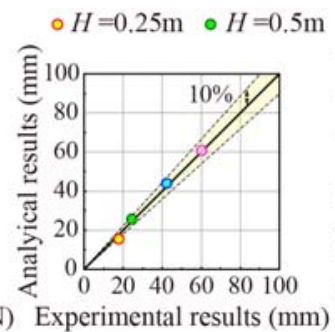

(c)

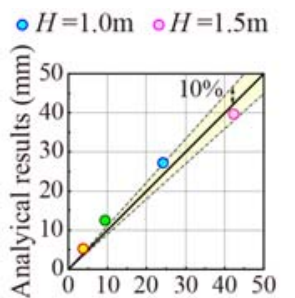

Experimental results (mm)

(d)

Figure 7: Comparisons between experimental and numerical results in case of using element size of $L=25 \mathrm{~mm}$. (a) Max. impact force; (b) Max. reaction force; (c) Max. deflection; (d) Residual deflection.

\subsection{Accuracy of numerical results}

Fig. 7 shows comparisons of maximum response values between numerical and experimental results in the case of using element size of $L=25 \mathrm{~mm}$. From Fig. 7(a), maximum impact forces obtained from the numerical analyses were about $20 \%$ smaller than those of experimental results. From Fig. 7(b), maximum reaction forces obtained from the numerical results were distributed within $20 \%$ errors. On the other hand, in the cases of maximum and residual deflections, it is observed that the numerical results were distributed within $10 \%$ errors.

\subsection{Crack patterns}

Fig. 8 shows comparisons between experimental and numerical results for crack patterns occurred on the side, top, and bottom-surfaces of the beams. Adopting constitutive law model for concrete as shown in Fig. 4(a), cracks were occurred in the elements when the tensile stress reached the cut-off value, and the stress in the element was lost. Here, applying this idea, crack occurred in the element will be predicted, in which the concrete element with zero stress was colored in red as shown in Fig. 8. Incidentally, in the case of $H=0.25 \mathrm{~m}$, crack patterns were not shown because no cracks were occurred due to smaller input impact energy.

From the experimental results, it is observed that: 1) the bending cracks near loading point were generated from the lower edge toward upper direction; 2) the radial spreading cracks from the loading point were more generated with an increment of the falling height of the weight; and 3) some vertical cracks were appeared on the top-surface, because the beam will behave so as to be fixed beam with small span length when the weight impacts onto the beam.

Comparing the crack patterns between the experimental and numerical results, it is observed that: 1) the bending cracks on the side surface and the diagonal cracks near loading point on the bottom surfaces were roughly better predicted irrespective of the magnitude of the falling height of weight; 2) on the top surface, although some cracks near the supporting points were observed in numerical results, the crack patterns were roughly better simulated; and 3) on the bottom surface, crack patterns obtained from numerical analysis tend to be evaluated more excessively than those of experimental results. 


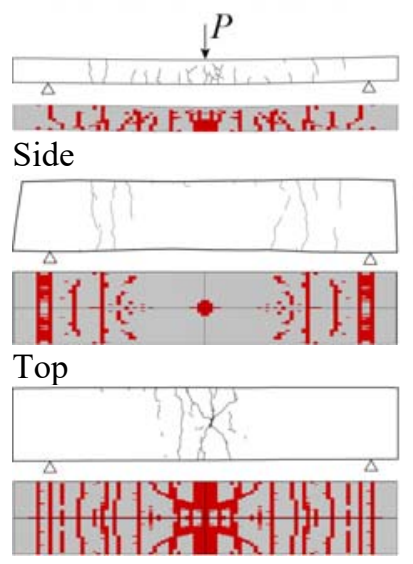

(a)
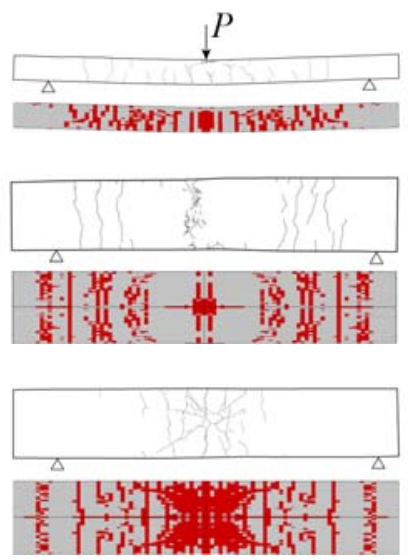

Bottom

(b)
Maximum principal stress $-\infty \quad-0.0010 .001 \infty$ (MPa)
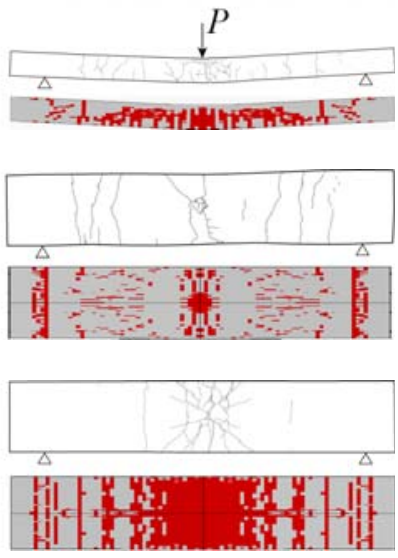

(c)

Figure 8: Comparisons of crack patterns of flat-shaped RC beams ( $L=25 \mathrm{~mm}$ ). (a) $H=$ $0.5 \mathrm{~m}$; (b) $H=1.0 \mathrm{~m}$; and (c) $H=1.5 \mathrm{~m}$.

\section{CONCLUSION}

1. Time histories of the dynamic responses of the flat-shaped $\mathrm{RC}$ beams can be better simulated using a fine mesh with $25 \mathrm{~mm}$ length in span direction.

2. Maximum and residual deflections can be better predicted irrespective of the magnitude of the falling height of the weight.

3. The crack patterns of the beams can be roughly better simulated applying the proposed numerical analysis method.

\section{REFERENCES}

[1] Takahashi, T., Yamamoto, Y., Katsuki, S. \& Takamori, K., Full scale experiments of falling rock protection net. Journal of Japan Society of Civil Engineers, 69(2), pp. 787798, 2013 (in Japanese).

[2] Yamaguchi, S., Kohata, Y., Komuro, M. \& Kishi, N., Falling-weight impact test for fullscale RC type rock-shed with sand cushion. Proceedings of the Japan Concrete Institute, 36(2), pp. 553-558, 2014 (in Japanese).

[3] Harada, S., Hoshino, K., Akioka, T., Komuro, M., Kurihashi, Y. \& Umezawa, H., The free-fall test of net protection system with Ring nets against tornado missile. Journal of Structural Engineering, 62A, pp. 1072-1083, 2016 (in Japanese).

[4] Kishi, N., Komuro, M., Kurihashi, Y., Mikami, H. \& Funaki, T., Experimental study on upgrading of impact resistant capacity for RC beams strengthened with NSM-AFRP rods. Journal of Structural Engineering, 63A, pp. 1188-1200, 2017 (in Japanese).

[5] Kishi, N. \& Bhatti, A.Q., An equivalent fracture energy concept for nonlinear dynamic response analysis of prototype RC girders subjected to falling-weight impact loading. International Journal of Impact Engineering, 37(1), pp. 103-113, 2010. 
[6] Komuro, M., Kishi, N., Ushiwatari, Y. \& Takeda, M., Impact response analysis of RC beams by means of fiber element approach. Proceedings of 5th International Workshop on Performance, Protection \& Strengthening of Structures Under Extreme Loading, pp. 595-602, 2015.

[7] Sakai, K., Kurihashi, Y., Konno, H. \& Kishi, N., Influence of setting a sand cushion on impact resistant behavior of flat-shaped RC beam. Proceedings of the Japan Concrete Institute, 38(2), pp. 787-792, 2016 (in Japanese).

[8] Hallquist, J.O., LS-DYNA Version R9 User's Manual, Livermore Software Technology Corporation, 2017. 